\title{
Iron Nitrate Modified Cotton and Polyester Textile Fabric Applied for Reactive Dye Removal from Water Solution
}

\author{
Jenny S. Komatsu, ${ }^{\oplus a, b}$ Beatriz M. Motta, ${ }^{a}$ Rodolfo S. Tiburcio, ${ }^{\oplus c}$ Ana M. Pereira Neto, ${ }^{c}$ \\ Pol W. G. de Pape, ${ }^{b}$ Dalmo Mandelli ${ }^{a}$ and Wagner A. Carvalho ${ }^{\circledR}, a$ \\ ${ }^{a}$ Núcleo de Tecnologias Sustentáveis, Centro de Ciências Naturais e Humanas, \\ Universidade Federal do ABC (UFABC), 09210-580 Santo André-SP, Brazil \\ ${ }^{b}$ Rigaku Latin America, 01255-000 São Paulo-SP, Brazil \\ ${ }^{c}$ Laboratório de Caracterização de Biomassa e Biocombustíveis, \\ Centro de Engenharia, Modelagem e Ciências Sociais Aplicadas, \\ Universidade Federal do ABC (UFABC), 09606-045 São Bernardo do Campo-SP, Brazil
}

\begin{abstract}
In this work, we investigated the use of cotton scraps in natura and modified with iron nitrate, in the adsorption of one of the main water contaminants of the textile industries, the reactive black dye. Special attention was paid to the appropriate destination of the spent adsorbent, in compliance with the precepts of the circular economy. Cotton and polyester are excellent candidates for adsorbents and are produced on a large scale worldwide, but fabric wastes do not yet have a wellestablished method of application. We found that fabrics containing different types of fibers or colors maintain the ability to remove dye. The retention promoted by the cotton fabric in natura reached $18.8 \mathrm{mg} \mathrm{g}^{-1}$. After treatment with iron ions, there was an increase in the dye adsorption capacity to $31.0 \mathrm{mg} \mathrm{g}^{-1}$. In addition, the spent iron-containing adsorbent was pyrolyzed at $973 \mathrm{~K}$, resulting in an activated magnetic carbon with a specific surface area ranging from 300 to $565 \mathrm{~m}^{2} \mathrm{~g}^{-1}$. Thus, it was possible to convert the used adsorbent into a new material with wide application possibilities.
\end{abstract}

Keywords: adsorption, fabric waste, reactive black dye, waste valorization, magnetic mesoporous activated carbon

\section{Introduction}

Many investigations have sought the use of low-cost by-products as adsorbents, focused on agro-industrial waste also as feedstock for fuel and chemical transformations, neglecting the potential of municipal solid wastes. Among them, textile fabric waste is increasing worldwide, driven by the growth of the middle-class population, and the "Fast Fashion" phenomena, with more than 38 million ton being sent to landfill or incinerated in a year. ${ }^{1}$ Brazil is the fifth largest textile producer and fourth in clothing production in the world. Cotton is still the most produced natural fiber worldwide, $81 \%$ in weight in 2018, and Brazil is the fifth largest producer. However, synthetic fiber consumption has grown very fast in the last decade, an increase in market share from 59 to $65 \%$, headed by polyester which has very low degradability in landfill. ${ }^{2}$ In 2018, 111 million tons

*e-mail: wagner.carvalho@ufabc.edu.br of fibers were produced in the world, $28 \%$ natural, $45 \%$ synthetic and $27 \%$ artificial, corresponding to 26.7 million tons of cotton and 45 million tons of polyester. ${ }^{3}$

In view of the circular economy principles, the destination of approximately $73 \%$ of the annual production of fabrics for landfill or incineration claims special attention. The recycling possibilities must be reviewed and improved, avoiding downcycling. Another major problem in the fashion industry is the high consumption of water, one of the largest in the industrial sector, and consequently large amounts of effluent are generated. Water consumption can reach ca. 150-350 L per $\mathrm{kg}$ of product, with the stream just after the dyeing operation being the most problematic, due to its intense color, higher $\mathrm{pH}$ and high salt concentration. ${ }^{4}$

Reactive dyes are the most produced and commercialized type of dye in the world and reactive black dye is the most used among them. ${ }^{5}$ Combined with the loss of the dye during the dyeing process, estimated between 10 and 50\%, conventional wastewater treatments have low efficiency 
in removing reactive dyes, which leads to the disposal of highly colored effluents. ${ }^{6}$ In our previous work, ${ }^{7}$ it was observed that iron impregnated cotton fabric had a good reactive black dye 5 (RB5) removal capacity.

Although adsorption is recognized as an easy, economical, environmentally friendly and low-cost technology for the removal and/or recovery of pollutants present in aqueous solutions, the final destination of the spent adsorbent must be carefully evaluated. In order to promote the sustainability of these processes, the valorization of spent adsorbents has been related to their use as fertilizers, additives for animal feed and catalysts, among others. In this sense, obtaining activated carbon from the spent adsorbent can be useful in both adsorption and catalysis processes. ${ }^{8}$ Commercial activated carbons are recognized as very good adsorbents, since they are able to retain a diversity of polluting species, among which aromatic and phenolic derivatives, pharmaceutics and dyes. However, commercial activated carbons are quite expensive and the search for new precursors for their production, such as agricultural and industrial waste, has been encouraged. ${ }^{9}$

There is a concern of material scarcity for activated carbon (AC) production as its demand is increasing worldwide mainly due to more stringent environmental laws. There are few studies ${ }^{9}$ using fiber and textile as raw material, compared to the large number of studies applying agro-industrial wastes. Moreover, from those published, there is no in-depth study of mixed fiber or colored fabrics effect. Polyester was activated by $\mathrm{MgCl}_{2} \cdot 6 \mathrm{H}_{2} \mathrm{O}$ leading to $1,307 \mathrm{~m}^{2} \mathrm{~g}^{-1}$ Brunauer, Emmett and Teller (BET) surface area $\left(\mathrm{S}_{\mathrm{BET}}\right)$, highly mesoporous carbon $(98 \%)$ with pore size concentrated at 16-20 nm range after $1173 \mathrm{~K}, 1.5 \mathrm{~h}$ pyrolysis. ${ }^{10} \mathrm{Yu}$ et al. ${ }^{11}$ also prepared activated carbon from polyester fabric and $\mathrm{ZnCl}_{2}$, resulting in a solid with $\mathrm{S}_{\mathrm{BET}}$ as high as $1,102 \mathrm{~m}^{2} \mathrm{~g}^{-1}$ and highly microporous (78\%). Both methods require post acid washing after the pyrolysis to eliminate $\mathrm{MgO}$ or $\mathrm{ZnO}$ formed during pyrolysis which is believed to be the template to pore development. Polyethylene terephthalate bottle wastes carbonization are more studied than polyester fabric, which have the same chemical structure. ${ }^{12}$ One of the few studies ${ }^{13}$ with mixed fibers used, separated cotton cloth and polyester cloth, mixed manually, to prepare carbons under nitrogen or carbon dioxide atmosphere, resulting in low methylene blue adsorption capacity of $2.8-3.5 \mathrm{mg} \mathrm{g}^{-1}$.

Magnetism is a hot topic in the development of new materials not only due to its easy to recover property in adsorption and heterogeneous catalysis, but also because magnetic nanoparticles may serve as catalyst itself, ${ }^{14}$ as for electrochemical applications increasing capacitance and electrical conductivity ${ }^{7,15}$ as well as enhance the electrical stability and durability. ${ }^{16}$ Furthermore, magnetic iron-based carbons can be efficiently used in the water treatment (including adsorption processes). Common preparation method of a magnetic porous carbon requires several steps, high temperature and long-time preparation. ${ }^{15-17}$ First, the magnetic compound is synthesized and then either encapsulated or deposited onto the previously carbonized structure. Mesoporous carbon support is usually obtained from template usage, which also requires several procedures steps, ${ }^{18}$ as the template preparation (commonly SBA-15), carbonization with the template, $\mathrm{NaOH}$ washing out of the SBA-15 to have the mesoporous, and finally the magnetic specie impregnation.

In our proposed method, iron specie is added into fabric, enhancing its color removal property, and then is directly incorporated into final carbon as ferromagnetic specie through pyrolysis without any other complex procedures, other than drying.

The aim of this study is to valorize the fabric wastes, solving another issue from the fashion industry itself. Cotton and polyester based fabrics were tested as adsorbents of reactive black dye, before and after impregnation with iron nitrate. The spent adsorbents were then pyrolyzed to produce magnetic activated carbon (MAC) in order to present an alternative to the disposal or incineration of the solid.

\section{Experimental}

\section{Materials and methods}

\section{Fabrics}

All fabrics were purchased at local fabric shop at Ipiranga District, São Paulo city, Brazil. Fabric names will be presented in full text when possible or abbreviated when necessary as follows: Poly (polyester), Cot (cotton), Poly/Elast ( $97 \%$ polyester/3\% elastane mix), Poly/Cot (50\% polyester $/ 50 \%$ cotton mix). Fabric color will be abbreviated as R (red) and W (white) before fiber type, when necessary. All fabrics chemical structures, composition and properties are presented in Figure S1 in the Supplementary Information (SI) section.

\section{Chemicals}

Iron nitrate (III) nonahydrate $\left(\mathrm{Fe}\left(\mathrm{NO}_{3}\right)_{3} \cdot 9 \mathrm{H}_{2} \mathrm{O}\right)$ ACS grade $\geq 98 \%$ was purchased from Sigma-Aldrich (São Paulo, Brazil), pellet sodium hydroxide $(\mathrm{NaOH}) \mathrm{PA} \geq 98 \%$ from Synth (Diadema, Brazil), sodium chloride $(\mathrm{NaCl}) \geq 99 \%$, from Refinaria Nacional de Sal S.A., was purchased at local market (Santo André, Brazil), a refined salt for domestic use. The colour index reactive black dye $5\left(\mathrm{RB} 5 ; \mathrm{C}_{26} \mathrm{H}_{21} \mathrm{~N}_{5} \mathrm{Na}_{4} \mathrm{O}_{19} \mathrm{~S}_{6}\right.$; 
wavelength of maximum absorbance $\left(\lambda_{\max }\right)=600 \mathrm{~nm}$; see Figure S2, SI section), from Esfera Química, was supplied by the industrial laundry company All Washed Lavanderia Industrial (Joanópolis, Brazil). Chemicals and fabric were used as received without further treatment. Distilled water was used through all experiments.

Iron impregnation

White cotton fabric was impregnated pouring a $5 \mathrm{~mL}$ water solution of $0.07 \mathrm{~g}$ Fe to each $1 \mathrm{~g}$ of fabric (corresponding to $0.5 \mathrm{~g}$ of iron nitrate), onto the open stretched fabric, and left to dry in an oven overnight at $333 \mathrm{~K}$.

Polyester and fiber mixed fabrics were cut in small pieces of about $1 \times 1 \mathrm{~cm}$, inserted in the iron nitrate solution of enough volume to the magnetic stirrer could move, with an equivalent $\mathrm{Fe}$ amount of 0.07 and $0.14 \mathrm{~g} \mathrm{~g}^{-1}$ Fabric and stirred for $1.5 \mathrm{~h}$ at room temperature. Fabrics were removed from the solution and left to dry in an oven overnight at 333 K. Fabrics were named with $\mathrm{Fe} 7$ and Fe14 after color and fiber type, for example, a red polyester fiber fabric impregnated with $0.07 \mathrm{~g} \mathrm{~g}^{-1}$ Fabric of Fe, is named RPolyFe7. Fabric used after dye adsorption process will be named with "Dye" at the beginning of the acronym as Dye.RPolyFe7.

\section{Synthetic dye wastewater preparation}

A stock solution of $5 \mathrm{~g} \mathrm{~L}^{-1}$ of RB5 and $75 \mathrm{~g} \mathrm{~L}^{-1}$ of $\mathrm{NaCl}$ was prepared and kept under refrigeration until use. At the time of use, the stock solution was diluted to $100 \mathrm{mg}_{\mathrm{RB}} \mathrm{L}^{-1}$ and the $\mathrm{pH}$ adjusted to 11 with $60 \% \mathrm{NaOH}$ solution. After that, it was left in the oven at $333 \mathrm{~K}$ for $1.5 \mathrm{~h}$, simulating the dye hydrolysis during dyeing process at industry. Finally, the solution was diluted 1:1 with distilled water, simulating dilution of the waste stream by other streams of a dyeing plant. Synthetic dye composition, $\mathrm{pH}$ and temperatures were defined to simulate a real industrial wastewater from fibber and fabric dyeing process. The procedure was adapted from Cunico et al. ${ }^{19}$ considering the wastewater characteristics collected by Silva et al. ${ }^{20}$ in a jeans dyeing factory in Brazil and by Bilińska et al. ${ }^{4}$ in Poland.

\section{Preliminary study}

Some "reference runs" were first performed. Starting synthetic dye solution of $50 \mathrm{mg} \mathrm{L}^{-1}$ was left under same conditions, stirring and heated at $313 \mathrm{~K}$, in $100 \mathrm{~mL}$ : (i) without any additives or adsorbent (dye solution); (ii) with $1.54 \mathrm{~mL}$ of $0.3 \mathrm{~mol} \mathrm{~L}^{-1} \mathrm{Fe}\left(\mathrm{NO}_{3}\right)_{3} \cdot 9 \mathrm{H}_{2} \mathrm{O}$ solution poured into the dye solution without fabric (Fe solution), (iii) $2 \mathrm{~g}$ of cotton fabric without Fe impregnation (fabric) and (iv) two different Fe impregnation rate cotton fabrics: $1 \mathrm{~g}_{\text {Fabric }}: 0.07 \mathrm{~g}_{\mathrm{Fe}}(\mathrm{Fe} 7)$ and $1 \mathrm{~g}_{\text {Fabric }}: 0.14 \mathrm{~g}_{\mathrm{Fe}}(\mathrm{Fe} 14)$. Iron nitrate solution volume to be poured was calculated to be similar to the amount of Fe present in the Fe7 cotton fabric. Samples were analyzed by UV-Vis spectrophotometry (PG Instruments, T80) in the spectrum range from 280 to $800 \mathrm{~nm}$. The color removal was estimated from the absorbance values at $600 \mathrm{~nm}$.

\section{Adsorption tests with cotton fabric}

The kinetic study was performed using $2 \mathrm{~g}$ cotton fabric impregnated with $\mathrm{Fe}$, poured in $1000 \mathrm{~mL}$ of $100 \mathrm{mg} \mathrm{L}^{-1}$ RB5 aqueous solution prepared as described in the previous section, under magnetic stirring with constant temperature of $313 \mathrm{~K}$. Aliquot of $5 \mathrm{~mL}$ of the solution was collected after time intervals from zero (right after pouring the fabric into the solution) to $4 \mathrm{~h}$, filtered with a $0.2 \mu \mathrm{m}$ filter, and stored in an amber glass, at each pre-defined time. Samples were analyzed by UV-Vis absorbance at $600 \mathrm{~nm}$ wavelength for color removal calculation. At the end of adsorption, fabric was recovered, dried at $343 \mathrm{~K}$ overnight, and stored for further use in pyrolysis. To evaluate the adsorption kinetic of reactive black dye onto the fabric, experimental data were fitted into the Lagergren pseudo-first order and pseudo-second order models. ${ }^{21}$ To verify if the adsorption mechanism is a particle diffusion controlled or film diffusion controlled, McKay-Poots intraparticle diffusion and Boyd diffusion models were also verified.22

Isotherm study was performed with $30 \mathrm{~mL}$ of synthetic dye solution prepared as previously described, varying absorbent mass from 16 to $50 \mathrm{~g}$ and dye concentration from 5 to $150 \mathrm{mg}_{\mathrm{RB} 5} \mathrm{~L}^{-1}$, to vary the starting dye mass to fabric mass rate from 3.9 to $112.6 \mathrm{mg}_{\mathrm{RB} 5} \mathrm{~g}_{\text {Fabric }}{ }^{-1}$. Temperature was controlled at $313 \mathrm{~K}$, and adsorption was performed for $2 \mathrm{~h}$. Starting and final color of solution was verified at $600 \mathrm{~nm}$ wavelength absorbance. Langmuir and Freundlich models were employed to verify the adsorption behavior. Experiments were performed under constant $\mathrm{pH}$ and temperature values, as the aim is to treat the textile wastewater as it comes out from the industry, with no further chemicals addition or energy input.

\section{Adsorption tests with polyester/cotton/elastane fiber mix fabrics}

White and red colored fabrics with the four different fiber types (Cot, Poly, Poly/Cot, Poly/Elast) were tested for adsorption capacity. All eight different fiber fabrics were impregnated with $\mathrm{Fe} 7$ and $\mathrm{Fe} 14$ in 10 to $20 \mathrm{~mL}$ of distilled water for each $1 \mathrm{~g}$ of fabric. The adsorbents were named Fe7 
and $\mathrm{Fe} 14$, followed by the fiber type. $1 \mathrm{~g}$ of adsorbent was poured in $100 \mathrm{~mL}$ of $50 \mathrm{mg} \mathrm{L}^{-1}$ synthetic dye, and was stirred at $313 \mathrm{~K}$ for $2 \mathrm{~h}$. Additionally to color removal, total organic carbon (TOC) measurement was performed to verify if the adsorbent used is degrading the dye, or just removing it from the solution. It was used a Shimadzu's TOC-LCPH/CPN model, that measures the amount of total carbon (TC), inorganic carbon (IC) and TOC in water.

\section{Magnetic activated carbon}

All 16 fabric types prepared with two different Fe impregnation rate and used as dye adsorbent, totalizing 32 fabrics, were carbonized at $973 \mathrm{~K}$ for $2 \mathrm{~h}$ under nitrogen atmosphere with a heating rate of $10 \mathrm{~K} \mathrm{~min}^{-1}$, followed by natural cooling under nitrogen until temperature reaches $373 \mathrm{~K}$. A tubular electric horizontal furnace with $5 \mathrm{~cm}$ diameter, with temperature control, quartz tubular reactor with quartz sample holder was used. Carbonized samples were identified according to acronyms described in sub-section "Iron impregnation", preceded by "MAC".

MAC with two different pore characteristics were tested as dye adsorbent itself. One with predominantly micropores and other predominantly mesopores. The dye solution used in this section of experiments was a simple water dissolved dye solution, with no $\mathrm{NaCl}$ adding, nor $\mathrm{pH}$ adjustment, nor thermal hydrolysis at $333 \mathrm{~K} .200 \mathrm{mg}$ of MAC was added to $100 \mathrm{~mL}$ of $100 \mathrm{mg} \mathrm{L}^{-1}$ black dye solution and left in a shaking table under room temperature for $4 \mathrm{~h}$. Aliquots were collected at $30 \mathrm{~min}, 1,2,3$ and $4 \mathrm{~h}$, filtered, stored and absorbance read at $600 \mathrm{~nm}$ for color removal.

\section{Characterization}

The point of zero charge $\left(\mathrm{pH}_{\mathrm{pzc}}\right)$ of the pure cotton fabric and iron modified cotton fabrics was determined as Mitrogiannis et al. ${ }^{23}$ The amount of Fe ions solubilized after $24 \mathrm{~h}$ of contact with aqueous solutions at different $\mathrm{pH}$ values, from 1.4 to 11 , were quantified by atomic absorption spectrometry (Analytik-Jena, contrAA300). Iron effectively impregnated on the fabric was quantified after aqua-regia extraction in digestion block, at $403 \mathrm{~K}$ for $2 \mathrm{~h}$, by wavelength dispersive X-ray fluorescence spectrometry (Rigaku, WDXRF Supermini200) and replicated in inductively coupled plasma optical emission spectrometry (ICP-OES). Eight $\mathrm{mL}$ of aqua-regia was used to $100 \mathrm{mg}$ of fabric with no Fe impregnated, and 20-60 mg of fabric impregnated with Fe. $100 \mu \mathrm{L}$ of the acid extracted solution was directly pipetted on the UltraCarry ${ }^{\circledR}$ filter, a very low noise and acid strong sample retainer, which allows to perform calibration curve. The filter was dried in low temperature, below $333 \mathrm{~K}$, for $4 \mathrm{~h}$ or less when possible.

Cotton fabrics before and after dye adsorption were characterized by Fourier transform infrared attenuated total reflectance (FTIR-ATR) spectroscopy by PerkinElmer Spectrum Two. Elemental analysis was performed in a Thermoscientific, FlashEA 1112 CHNS Analyzer. Powder $\mathrm{X}$-ray diffraction analysis (DRX) was carried out in a Rigaku Miniflex600 benchtop diffractometer, $40 \mathrm{kV}, 15 \mathrm{~mA}$ with D/Tex ultra-fast and high resolution $1 \mathrm{D}$ detector. A sample containing less than $50 \mathrm{mg}$ was loaded in a $\mathrm{Si}$ crystal sample holder of a very low background. Thermal behavior of the fabric samples, with and without $\mathrm{Fe}$ or dye were examined by thermogravimetric and differential thermal analysis (TG/DTA) with a Shimadzu DTG60-H system under $\mathrm{N}_{2}$ atmosphere, $10 \mathrm{~K} \mathrm{~min}^{-1}$ heating rate. The specific surface area and pore-size distribution were estimated in a Quantachrome Autosorb 1MP device. The samples were prior degassed under vacuum for at least $4 \mathrm{~h}$ at $573 \mathrm{~K}$. The morphology and surface elemental analysis were performed in an energy dispersive spectroscopy (EDS) chemical microanalysis module coupled to a JEOL JSM-6010la compact scanning electron microscope. Surface elemental composition and oxidation information was analyzed by the X-ray photoelectron spectroscopy (XPS) equipment from ThermoFisher Scientific, model $\mathrm{K}$-alpha+, which measurements detailed can be found in our previous work. ${ }^{7}$ The magnetic property was measured in a magnetic property measurement system, superconducting quantum interference device with vibrating sample magnetometer (MPMS Squid-VSM), EverCool C060 model from Quantum Design. Besides the standard moment versus field $(\mathrm{M} \times \mathrm{H})$, variation of the external magnetic field at room temperature, a $\mathrm{M} \times \mathrm{T}$, temperature variation at a constant magnetic field was also performed, for heating to high temperature up to $950 \mathrm{~K}$. Amount of Fe effectively impregnated on MAC was quantified by the same procedure used for the fabrics, as previously described. $8 \mathrm{~mL}$ of aqua-regia was used to $30-60 \mathrm{mg}$ for activated carbon with $\mathrm{Fe}$. The medium was centrifuged, and the supernatant was separated for analysis.

\section{Results and Discussion}

\section{Preliminary study}

The reference test with the cotton fabric without $\mathrm{Fe}$ impregnated (Figure S2a, SI section) resulted in very low color removal capacity ( $23 \%$ in $3 \mathrm{~h}$ ) measured at $600 \mathrm{~nm}$. While the Fe solution resulted in instant removal of $92 \%$ at $600 \mathrm{~nm}$, remaining a low blue color adsorption at $484 \mathrm{~nm}$. 
Color removal by $\mathrm{Fe} 7$ and $\mathrm{Fe} 14$ fabrics were also instant (Figure S2b, SI section), with 87-92\% removal at $600 \mathrm{~nm}$ and $80-87 \%$ at $484 \mathrm{~nm}$. After $15 \mathrm{~min}$, there is virtually no color remaining, but it was noted a significant absorption increase in the ultraviolet region, which could indicate a possible fragmentation of the dye structure to aromatic compounds. This will be further verified through total organic carbon analysis. The UV-Vis spectrum of the dye solution in contact with the iron nitrate solution is very close to those obtained after treatment with $\mathrm{Fe} 7$ and $\mathrm{Fe} 14$, indicating that a similar color removal mechanism may be involved.

\section{Adsorption by white cotton fabric: kinetics and isotherm}

Kinetic studies (experimental data and kinetic models) of RB5 adsorption onto Fe7 cotton fabric are presented in Figure 1. The fitting parameters of the kinetic models are available in the SI section (Table S1).

As is possible to observe in Figure 1a, a fast color removal occurs in the first 10 min contact time between the adsorbent and the dye solution, and then equilibrium is reached at $1 \mathrm{~h}$. Adsorption kinetics for pseudo first-order model resulted in low correlation value $\left(R^{2}=0.748\right)$, fitting better to the pseudo-second order model $\left(\mathrm{R}^{2}=0.999\right.$, pseudosecond order rate constant $\left(\mathrm{K}_{2}\right)=0.012 \mathrm{~g} \mathrm{mg}^{-1} \mathrm{~min}^{-1}$, dye adsorption capacity at equilibrium $\left.(\mathrm{Qe})=21 \mathrm{mg}_{\mathrm{RB} 5} \mathrm{~g}_{\text {Fabric }}{ }^{-1}\right)$. This suggest that the rate limiting step may be chemical adsorption or chemisorption involving valence forces through sharing or exchange of electrons between adsorbent and adsorbate. ${ }^{24}$

Most of the kinetics and diffusion models considers a spherical homogeneous adsorbent particle, as well as porous materials. The adsorbent used in this study is characterized by a long fiber, non-porous material. Therefore, these commonly applied models will not give us exact information but can give some insight into the adsorption mechanism.
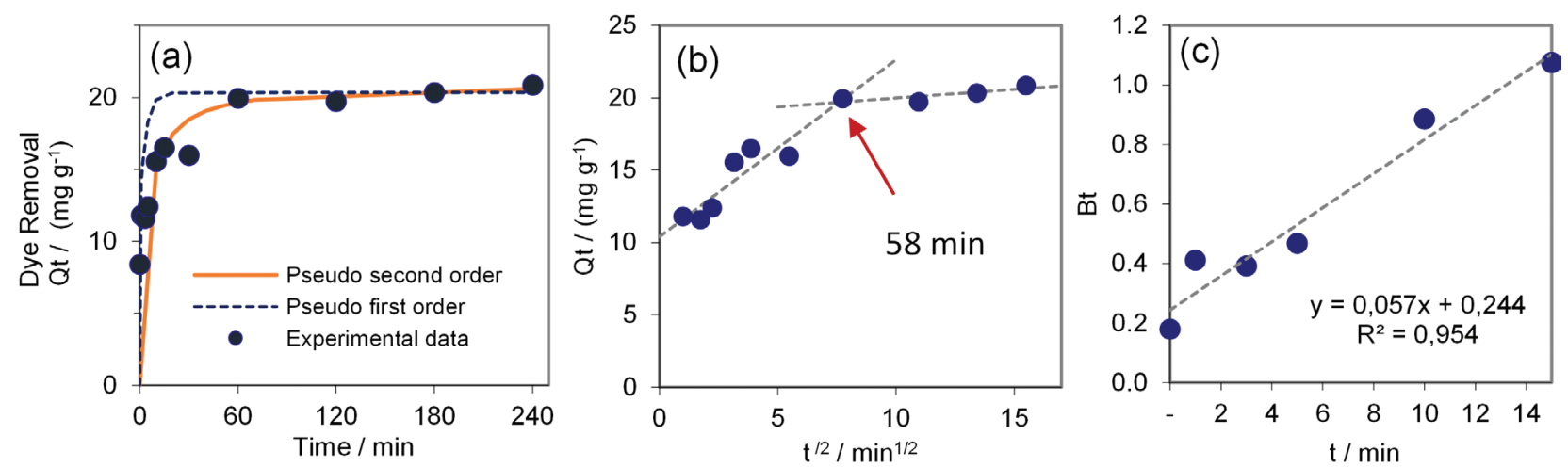

Figure 1. Reactive black dye adsorption by white cotton fabric + Fe. Temperature: $313 \mathrm{~K}$; initial pH: 10; starting dye/adsorbent $=50 \mathrm{mg} \mathrm{g}{ }^{-1}$. (a) $\mathrm{Kinetic}$ curves, (b) intraparticle diffusion model, (c) Boyd particle diffusion model. Qt and Bt are the adsorption capacity at time $\mathrm{t}$ (min) and a mathematical function of Qt/Qe calculated by the Boyd model, respectively.
In general, McKay-Poots intraparticle diffusion model plot is multilinear, indicating how many steps are involved in the adsorption process. ${ }^{25}$ According to the Figure $1 \mathrm{~b}$, it is possible to point out two linear sections. The first one, up to $58 \mathrm{~min}$, can be attributed to the diffusion process of dye to the absorbent surface, while the second line is regarded as the establishment of equilibrium. When intraparticle diffusion is the only rate-controlling step in the adsorption, a straight line should pass through the origin. Since this behavior was not observed, we can consider that the intraparticle diffusion is not a determinant of the rate (as expected for a non-porous adsorbent).

The extent of deviation from zero of the first linear portions (linear coefficient of the intraparticle diffusion model $(\mathrm{C})=10.4$ ) is proportional to the boundary layer thickness. Boundary layer gives indication of the ability of the adsorbents to remove the target pollutant from solution. It is also seen as viscous drag which exists between the sorbent surface and dye molecules diffusing across the boundary layer. The boundary effect could be related to the iron complexes film formed on the cotton surface, as explained further. In this case, the film diffusion was the rate limiting process. ${ }^{26}$

Boyd diffusion model was studied in addition to the intraparticle diffusion model, as the late one does not give information for the first minutes of the process. Boyd plot (Figure 1c) did show a good fit $\left(\mathrm{R}^{2}=0.954\right)$. However, the linear coefficient value does not approach zero, indicating that intra-porous diffusion is not the rate determinant process at the first minutes of contact. Therefore, film diffusion is the main process involved in the dye removal by the CotFe.

The isotherm experiments were performed with the $\mathrm{Fe} 7$ cotton. Results are presented in Figure 2a. Fe7 fitted well to the Langmuir model $\left(\mathrm{R}^{2}=0.967\right)$ meaning a monolayer adsorption mechanism, with $\mathrm{R}_{\mathrm{L}}$ (separation factor) of 0.025 to 0.45 . Values of $R_{L}$ varying from 0 to 1 means the adsorbate has more affinity to the solid adsorbent than

function of Q 
the liquid phase, and the adsorption process is favorable. Maximum adsorption capacity (Qmax) was found as $31 \mathrm{mg}_{\mathrm{RB} 5} \mathrm{~g}_{\text {Fabric }}{ }^{-1}$.

\section{Adsorption by white cotton fabric: $\mathrm{pH}$ influence}

The $\mathrm{pH}$ of dye solution decreased from alkaline to 2.7-3.9 after $2 \mathrm{~h}$ contact time with the fabrics. The $\mathrm{pH}$ of the solution usually plays a major role in the adsorption process, since it affects the solution chemistry of dyes and the activity of the functional groups of the adsorbent. Usually, reactive dyes demand strong acidic conditions for optimum dye adsorption..$^{27}$ Therefore, adsorption test with pure cotton fabric in an acid dye solution was performed to verify the influence of a low $\mathrm{pH}$ value. When the $\mathrm{pH}$ value was adjusted to 2.5 , it was possible to reach a relatively high Qmax of $18.8 \mathrm{mg} \mathrm{g}^{-1}$ (Figure 2b), and it was observed that fabric alone requires a minimum dye concentration of $20 \mathrm{mg} \mathrm{L}^{-1}$ to allow the start of the adsorption process. In this case, none of the adsorption models fit well, with a $\mathrm{R}^{2}$ of 0.456 and 0.848 for Langmuir and Freundlich, respectively. However, Freundlich model could be applied for modeling with a limitation of concentration range from 20 to $80 \mathrm{mg} \mathrm{L}^{-1}$, improving the correlation $\mathrm{R}^{2}$ to 0.945 .

The relatively high color removal by pure cotton at $\mathrm{pH} 2.5$ can be explained by the change of the surface charge of the cotton fabric according to the $\mathrm{pH}$ of the solution. Cotton has two points of charge alternation, one at high $\mathrm{pH}$ of 9.1 and another at low $\mathrm{pH}$ of 2.1 (Figure S4, SI section). Between the $\mathrm{pH}$ range of 2.1 to 9.1 , the cotton surface is negatively charged due to the deprotonation and formation of $\mathrm{C}_{-} \mathrm{O}^{-}$, and at $\mathrm{pH}$ higher than 9.1 and lower than 2.1, the surface charge is slightly positive. In the $\mathrm{pH}$ region close to 2.5 , protonation of the surface of pure white cotton results in regions of positive charge, favoring its interaction with the reactive black dye, of a negative nature. When iron is impregnated on the fabric, a positively charged surface is observed over a wide range of $\mathrm{pH}$ values, from highly

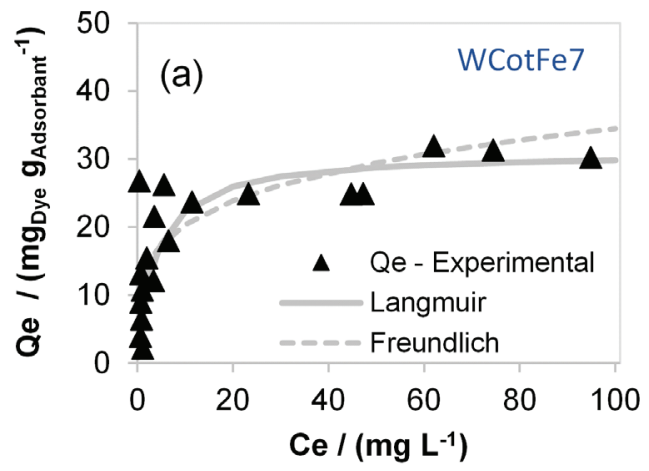

alkaline until 2.3 , and below $\mathrm{pH}_{\mathrm{PZC}}$ it is slightly negative to neutral.

The dye used in this study has $\mathrm{p} K_{\mathrm{a}}$ at $\mathrm{pH}<0$ for the sulfur groups, ${ }^{28}$ at 3.8 for the $-\mathrm{NH}_{2}$ groups and at $6.9,{ }^{29}$ resulting that the dye molecule maintains its negative charge even in very low $\mathrm{pH}$ values, and at $\mathrm{pH}$ lower than 3.8 it got the highest negative charge. Therefore, the favorable electrostatic interactions between the $\mathrm{CotFe}$ and RB5 are present in a large $\mathrm{pH}$ values range, from highly alkaline to 2.3 .

Adsorption by white cotton fabric: adsorption mechanism hypothesis

The initial assumption for the removal of the color in this system is believed to be a conjunction of three mechanism: ( $i$ ) protonation of the fabric, charging positively the surface due to the $\mathrm{pH}$ reduction, enhancing interaction with negative reactive dye, (ii) coagulation due to the iron dissolved into the solution from the fabric and (iii) coagulation from the iron aquacomplexes formed on the fabric surface itself.

Fe impregnated cotton has free $\mathrm{HNO}_{3}$ molecules from the iron nitrate used. The iron nitrate is hydrolyzed into $\mathrm{Fe}(\mathrm{OH})_{2} \mathrm{NO}_{3}$ and $\mathrm{HNO}_{3}$ when it is dried in the oven (equation 1). ${ }^{30}$ Nitric acid remains on the fabric, as the drying is performed at $333 \mathrm{~K}$, while its boiling point is $356 \mathrm{~K}$. Also, the other nitrate ions should be hydrolyzed when in contact with the liquid solution (equation 2), releasing three molecules of $\mathrm{HNO}_{3}$ for each iron impregnated on the fabric into the dye solution, decreasing drastically the $\mathrm{pH}$ value to $3-4$. The experimental mass loss values obtained by TG (19.5\%) and by oven heating (20\%) are consistent with the theoretical value predicted for these conversions (19.8\%).

$$
\begin{aligned}
& \mathrm{Fe}\left(\mathrm{NO}_{3}\right)_{3} \cdot 9 \mathrm{H}_{2} \mathrm{O} \rightarrow \mathrm{Fe}(\mathrm{OH})\left(\mathrm{NO}_{3}\right)_{2} \cdot \mathrm{H}_{2} \mathrm{O}+ \\
& 7 \mathrm{H}_{2} \mathrm{O}_{(\mathrm{g})}+\mathrm{HNO}_{3} \\
& \mathrm{Fe}(\mathrm{OH})\left(\mathrm{NO}_{3}\right)_{2} \cdot \mathrm{H}_{2} \mathrm{O} \rightarrow \mathrm{Fe}(\mathrm{OH})_{3}+2 \mathrm{HNO}_{3}
\end{aligned}
$$

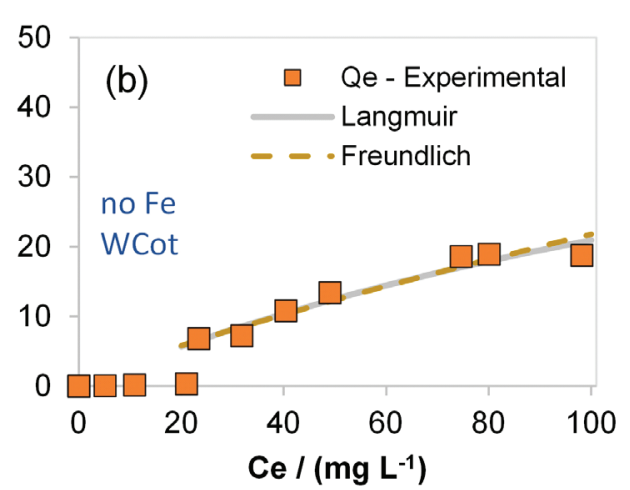

Figure 2. Reactive black dye adsorption isotherms at $313 \mathrm{~K}, 2$ h contact, with Langmuir and Freundlich models fitting curves. (a) WCotFe7 in pH 10 , (b) pure cotton in $\mathrm{pH}$ 2.5. Qe is the dye adsorption capacity and $\mathrm{Ce}$ is the dye concentration in solution in equilibrium. 
Iron (III) hydroxide is commonly found in the hydrated form $\mathrm{FeO}(\mathrm{OH}) \mathrm{H}_{2} \mathrm{O}$. Then, successive reactions of hydrolysis and formation of mono and polynuclear aquacomplexes with trivalent iron metal centers occurs. The complex specie is directly related to the $\mathrm{pH}$ of the solution and the concentration of the iron ion. At slightly acid or neutral $\mathrm{pH}$ values, positively charged or electroneutral metal hydroxide colloids are formed, whereas at higher $\mathrm{pH}$ values, the negatively charged species are formed. ${ }^{31}$

\section{Iron leaching to the solution}

At first, it was considered that part of the iron would be released by the fabric as soon as the adsorbent was in contact with the dye solution, immediately forming $\mathrm{Fe}-\mathrm{OH}$ aquacomplexes. These are known coagulants in water and wastewater (Figure S5, SI section). ${ }^{32}$ As the dye solution has high amount of $\mathrm{OH}^{-}$, the aquacomplex formation is even more enhanced. It was observed that in some cases, it is formed a very fine black powder (Figure S6a, SI section) after color removal by the Fe fabrics. The powder was recovered by centrifugation from the dye solution and analyzed on XRD and scanning electron microscopy (SEM).

XRD resulted in a pure $\mathrm{NaCl}$ diffractogram, with no dye presence, probably due to the high concentration of a highly crystalline phase of $\mathrm{NaCl}$ which gives very intense peak signal in diffractogram, hiding other components signal. However, the presence of dye solution in the coagulated material was verified visually by liquid-liquid extraction. The coagulated dye solution was extracted by organic solvent (a mixture of dichloromethane and toluene) and verified that the organic solvent turns into blue color, indicating the dye presence.

However, a closer observation of the coagulated powder by SEM, revealed that it was not a powder of iron aquacomplexes and dye with $\mathrm{NaCl}$, but a very fine and small fibers agglomeration with dye adsorbed on it (Figure S6b, SI section). The Fe and $\mathrm{S}$ element map scanning by EDS (Figures S6c and S6d, SI section) demonstrates that the mechanism of iron aquacomplex might be occurring on the surface of the fibers.

Although, when CotFe7 is put in contact with varied $\mathrm{pH}$ water solutions, it was observed a high Fe leaching of $27.5 \pm 2.7 \%$ in average from pH 3 to 11 (Figure S7, SI section), the same was not confirmed when CotFe7 is put in contact with synthetic dye solution. The Fe dissolution amount was not measured directly, but $\mathrm{Fe}$ content on the fabrics after dye adsorption was measured by acid extraction and WDXRF UltraCarry ${ }^{\circledR}$ method, replicated on ICP-OES (Table S2, SI section). In CotFe7 it was estimated an $\mathrm{Fe}$ amount of $3.49 \pm 0.25 \mathrm{wt} . \%$, and in Dye.CotFe7 $5.08 \pm 0.13$ wt. \%, both values close to the mathematically calculated one. Therefore, from these data, there is no evidence that $\mathrm{Fe}$ is leaching into the solution as we supposed at beginning, supporting our theory that iron aquacomplexes must be forming on the fabric surface itself. These iron aquacomplexes coagulated with the dye molecules should inhibit the dissolution of Fe into the water as free ion $\mathrm{Fe}^{3+}$. Moreover, salts presence (as $\mathrm{NaCl}$ ) seems to enhance dye removal capacity. ${ }^{33}$ This fact eliminates the concern of iron ion leaching into the environment, as iron is very tightly linked to the fabric.

Iron-containing adsorbents are widely used for heavy metal cations removal from aqueous solution but are not efficient for removing anionic compounds. ${ }^{18,34}$ Cationization of cellulosic fiber was attempted by Ferrero and Periolatto ${ }^{35}$ to enhance dye adsorption capacity. Several chemicals and processes were efficiently applied to cotton products to obtain a positive charged adsorbent, but they are very expensive. In our work, the cationization occurs in situ, i.e., when the fabric is poured into the aqueous solution, a cationization of the fabric surface by protonation, and the positive charged aquacomplex formation occurs. Moreover, hydrolyzed dyes have hydroxyl group available to form hydrogen bond with the cellulose surface. Additionally, the interactions present in the normal dyeing process between dye and cellulose fiber should also exist in lower extents: the covalent bond between dye Dye- $-\mathrm{CH}_{2}-\mathrm{CH}_{2}{ }^{\cdot}$ and cellulose $\mathrm{O}^{-}$, and hydrogen bond between hydrolyzed dye Dye $-\mathrm{CH}_{2}-\mathrm{CH}_{2}-\mathrm{OH}$ and cellulose.

\section{Complementary characterizations for cotton fabric adsorbent}

XRD was performed for cotton fabric before and after dye adsorption (Figure S8). However, the cellulose crystalline signal is too high, blocking any other signals for the dye. For an attempt to observe an interaction between the dye and cellulose, it was compared the crystallinity index (CI) estimated by the signal height method (Table S3). ${ }^{36}$ There was a large decrease in the signal response from pure cotton to iron impregnated cotton, but no significant decrease in the $\mathrm{CI}$, from 0.954 to 0.872 . This difference cannot be considered significant, as there are errors involved in the estimation of the intensity height due to background differences between the samples. After the dye adsorption, occurred the same decrease in signal but not in CI (0.972). Therefore, it can be considered that the signal decrease is due to the adsorbate layers formed on the cotton surface, 
first by the iron nitrate, and then by the iron aquacomplex and captured dye into the aquacomplex. Kyzas et al. ${ }^{36}$ considered that as high is the crystallinity, the higher was the dye adsorption capacity, attributed to the cellulosic content of the fiber applied in that study.

FTIR spectra from the cotton with and without iron, and before and after adsorption (Figure S9, SI section) were compared. The only visible change in a qualitative manner is a relative increase in the range $1725-1500$, related to $\mathrm{C}=\mathrm{O}$ on ester, amide, $\mathrm{NH}$ amides and amines. As cotton is pure cellulose, which does not have ester groups, the broadening on this range after the dye adsorption, could indicate the $-\mathrm{NH}$ and $-\mathrm{NH}_{2}$ groups of the dye. It was not observed shift in -OH (3600-3000 $\left.\mathrm{cm}^{-1}\right)$ as proposed by Kyzas et al. ${ }^{36}$ which would indicate hydrogen bond between fiber and dye, but this does not exclude the possibility.

XPS wide scan presented S2p signal only in the fabrics after dye adsorption, and high resolution scan at $\mathrm{S} 2 \mathrm{p}_{3 / 2}$ and its spectrum deconvolution lead to three components, all relating $\mathrm{C}$ to $\mathrm{S}: \mathrm{C}-\mathrm{SO}_{2}$ at $167.9 \mathrm{eV},=\mathrm{CS}$ at $168.7 \mathrm{eV}$ and $\mathrm{H}_{3} \mathrm{C}-\mathrm{S}$ at $170 \mathrm{eV}$ (Figure S10, SI section), all, dye structure related components, showing that the dye is actually adsorbed on the surface of the fabric at different points of the cellulose.

\section{Adsorption by other fabrics (polyester and its mix fibers)}

From the previous section, it was verified that in one hour the system is in equilibrium in the case of white cotton fabric. As colored fibers or synthetic fibers could give lower removal capacity, the tests for the different fabrics were done with $2 \mathrm{~h}$ reaction time to guarantee equilibrium. Figure 3 exhibits color removal and total organic carbon (TOC) removal for the 4 different fiber blend fabrics with 2 different fiber colors (white and red) and 2 different $\mathrm{Fe}$ impregnation ratios (0.07 and 0.14$)$.

Highest color removal of $96.0 \pm 3.9 \%$ was achieved by polyester/elastane blend fabric, which is very unexpected, as elastane is known to be highly water repellant. ${ }^{37}$ The external polyester fiber should be damaged by the high alkaline and subsequent acidic environment, exposing the internal elastane fiber. Therefore, the elastane urethane segments must be forming hydrogen bonds with the hydroxyl groups of the hydrolyzed dye, enhancing dye removal rate.

However, this extreme $\mathrm{pH}$ change lead also to the hydrolysis of the silicone coating of the elastane, enhanced by the high concentration of chloride ions which also attack the silicone. These facts resulted in a low TOC removal by Poly/Elast fabrics, not because the color is not removed from the solution, but because there is a release of another source of carbon from silicone coating. A Si particle was observed on the Poly/Elast derived MAC (Figure S11, SI section).

Pure polyester had similar color removal capacity of pure cotton, in average $84.6 \pm 13.7 \%$ color removal and $85.5 \%$ TOC removal. However, it was observed a poor distribution of the Fe among the fabric surface of polyester, with spots of different shades after the Fe impregnation, which may have caused the high deviation among the runs. This shade difference was not observed in the Poly/Elast fabrics, and it reflected in the lower deviation between the runs of $\pm 3.9 \%$. Polyester fiber has a high orientation structure, making difficult the dye to penetrate the fiber, thus requiring more energy to dye it. ${ }^{38}$

Polyester blend into the cotton also caused the heterogeneity on the $\mathrm{Fe}$ distribution on fabric surface, leading to the poorest result among our studies $(57.5 \pm 21.9 \%)$. Fiber mixture are in general made during the spinning process (when the fibers are converted into the long yarns), therefore the hydrogen bonds of the cellulose from cotton should be less available for interactions compared to pure cotton fabric decreasing the color removal capacity.

The increase in the amount of Fe impregnated did not increase proportionally the dye removal capacity, even decreasing the capacity in the case of white polyester and white Poly/Cot. This can be explained by the weak impregnation capacity of the Fe ion in the synthetic fiber. For the Fe14 series, after drying a large part of the Fe was observed as a loose powder from the fabric.

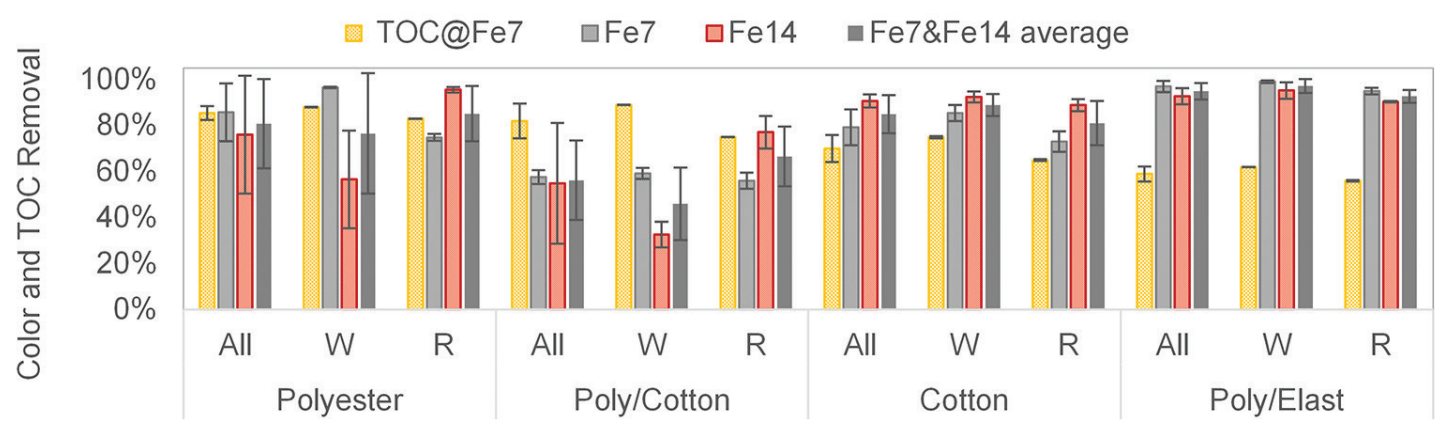

Figure 3. Reactive black dye removal capacity comparison between cotton/polyester/elastane fiber fabrics. Color removal at $600 \mathrm{~nm}$ and TOC removal. 


\section{Magnetic activated carbon}

All fabrics used to prepare adsorbents, as well as the spent adsorbents after dye removal, were pyrolyzed to produce activated carbon. The average $S_{B E T}$ grouped in the two different $\mathrm{Fe}$ impregnation rate and with or without dye adsorption are plotted in Figure 4. As observed in our previous work, ${ }^{7}$ it was confirmed that the dye adsorption process contributes to enhance the pore development (mean value of $498 \mathrm{~m}^{2} \mathrm{~g}^{-1}$ ) compared to the adsorbent without dye (mean value of $361 \mathrm{~m}^{2} \mathrm{~g}^{-1}$ ).

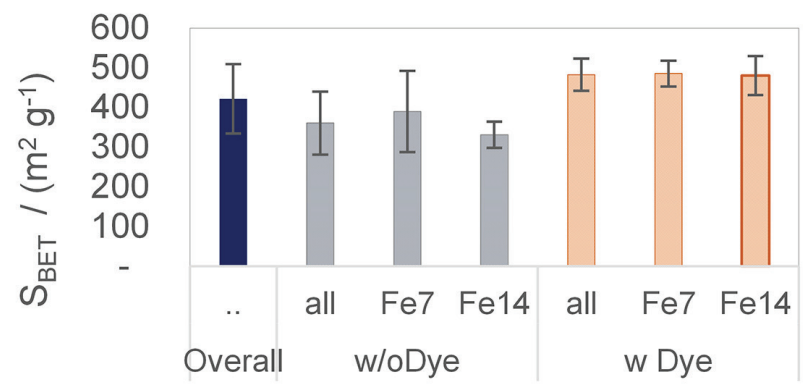

Figure 4. Average BET surface area comparison of MAC produced from different fiber blend fabrics, grouped in two different Fe impregnation ratio (Fe7 and Fe14), with (w) and without (w/o) dye adsorption.

The increase in the surface area is believed to be due to the incorporation of the dye molecules on the fabric, enhancing carbon yield. It is confirmed by the thermal gravimetry analysis (TG) of the fabrics (Figure S12, SI section) which in the case of white cotton, the residual mass at $1073 \mathrm{~K}$ was $20.6 \%$ in the WCotFe7 and $7.5 \%$ in the Dye.WCotFe7. This decrease in the residual mass after total thermal degradation was observed in all fabric types. Carbon content in the fabrics also confirms this fact. From elemental analysis, carbon content increased from 30.3 wt.\% in WCotFe7 to 35.4 wt.\% in Dye.WCotFe7 (Table 1).

The deviation between the two Fe impregnation ratio is larger in the MAC derived from non-dye adsorbed fabrics. In general, a higher $\mathrm{Fe}$ impregnation led to decrease in $\mathrm{S}_{\mathrm{BET}}$, probably due to the obstruction of the pores by the additional $\mathrm{Fe}$, but this effect is minimized in the solid submitted to the dye adsorption. There was a reduction of $15 \%$ in the $\mathrm{S}_{\mathrm{BET}}$ value in MAC and of $1 \%$ in MAC. Dye from $\mathrm{Fe} 7$ to Fe14. The exception was the pure cotton derived MAC.Dye which $\mathrm{S}_{\mathrm{BET}}$ increased in $10 \%$ for white fiber and $15 \%$ for red fabric, from $\mathrm{Fe} 7$ to $\mathrm{Fe} 14$, reaching the maximum value achieved in our study $\left(565 \mathrm{~m}^{2} \mathrm{~g}^{-1}\right)$. This result demonstrates that cellulose has good interaction with Fe ions. A comparison of $\mathrm{S}_{\mathrm{BET}}$ for all individual $32 \mathrm{MAC}$ produced from the different combination fabrics are available in SI section (Figure S13).
Table 1. Elemental analysis of red polyester and white cotton before and after dye adsorption. $\mathrm{S}$ content of all samples was below calibration curve range

\begin{tabular}{lccc}
\hline Material & C / wt. $\%$ & H / wt. $\%$ & N / wt. $\%$ \\
\hline RPolyFe7 & $42.6 \pm 5.1$ & $3.4 \pm 0.2$ & $2.3 \pm 0.2$ \\
Dye.RPolyFe7 & $60.1 \pm 0.2$ & $4.4 \pm 0.3$ & $0.4 \pm .0 .2$ \\
WCotFe7 & $30.3 \pm 1.0$ & $5.20 \pm .0 .3$ & $2.02 \pm 0.3$ \\
Dye.WCotFe7 & $35.4 \pm 0.3$ & $5.6 \pm 0.2$ & $0.23 \pm 0.2$ \\
\hline
\end{tabular}

More detailed characterization was performed with four MAC, all for Fe7: two with fabrics without dye adsorption step, red cotton and white Poly/Elast and two with fabrics with dye adsorption step, red polyester and red Poly/Elast. Poly/Cot mixture fiber fabric was not chosen for detailed characterization, as they had the lowest removal capacity and also low pore development. Pore and elemental properties of MAC for the selected Fe7 fabrics are presented in Table 2. Additional plots of XRD diffractogram, density functional theory (DFT) pore size distribution and magnetization curves are available in SI section (Figure S14).

Although they are all different fiber/color type fabrics, the tendency remains, with higher pore development and lower average micropore size $(1.065 \mathrm{~nm})$ for the MAC derived from the fabrics that went through the dye adsorption step. With exception of RCot, all others developed mesopores on the 4-5 nm range. Dye adsorbed fabrics developed metallic iron species according to XRD results in contrast to the non-dye adsorbed fabrics which developed oxide iron (magnetite) specie. This difference in the iron species leads to difference in the response to an external magnetic field where MACs with iron oxide have lower magnetization saturation (Ms) than MAC with metallic iron. Ms for MAC.Dye.RCot and MAC. Dye.RPoly/Elast were 38.2 and $47.5 \mathrm{emu} \mathrm{g}^{-1}$ respectively, while Ms were 27.6 and $24.3 \mathrm{emu} \mathrm{g}^{-1}$ for MAC.RPoly and MAC.WPoly/Elast, respectively. Iron reduction into its elemental metallic form is usually achieved using a chemical reductor or $\mathrm{H}_{2}$ heating treatment. As explained previously, heating pure iron nitrate $\left(\mathrm{Fe}\left(\mathrm{NO}_{3}\right)_{3} \cdot 9 \mathrm{H}_{2} \mathrm{O}\right)$, under inert atmosphere, releases water and nitric acid and quickly degrades into iron oxide up to $433 \mathrm{~K} .{ }^{30}$ The oxidation does not require oxygen from the atmosphere, utilizing the oxygen from its own structure, the nitrate. Like in this case, the normal thermal transformation of $\mathrm{Fe}$ under inert atmosphere is to form carbides $\left(\mathrm{Fe}_{\mathrm{x}} \mathrm{C}_{\mathrm{y}}\right)$ in the presence of $\mathrm{C}$ and/or to oxides if there is oxygen, not necessary as gaseous dioxygen. When heated above $1073 \mathrm{~K}$ it starts to turn into metallic Fe if there is no oxygen presence. ${ }^{39}$ 
Table 2. Pore and elemental properties of MAC, for selected fabrics Fe7

\begin{tabular}{|c|c|c|c|c|}
\hline & \multicolumn{2}{|c|}{ Without dye } & \multicolumn{2}{|c|}{ With dye } \\
\hline & Red Cotton & White Poly/Elast & Red Poly & Red Poly/Elast \\
\hline \multicolumn{5}{|c|}{ Pore characteristic } \\
\hline $\mathrm{S}_{\mathrm{BET}} /\left(\mathrm{m}^{2} \mathrm{~g}^{-1}\right)$ & 458 & 368 & 456 & 486 \\
\hline $\operatorname{Diam}_{\text {MICRO }} / \mathrm{nm}$ & 1.21 & 1.21 & 1.07 & 1.06 \\
\hline $\mathrm{V}_{\text {TOTAL }} /\left(\mathrm{cm}^{3} \mathrm{~g}^{-1}\right)$ & 0.248 & 0.268 & 0.280 & 0.317 \\
\hline $\mathrm{V}_{\text {MICROPORES }} /\left(\mathrm{cm}^{3} \mathrm{~g}^{-1}\right)$ & 0.175 & 0.143 & 0.185 & 0.192 \\
\hline$\underline{\mathrm{V}_{\text {MESOPORES }} /\left(\mathrm{cm}^{3} \mathrm{~g}^{-1}\right)}$ & 0.073 & 0.125 & 0.095 & 0.126 \\
\hline \multicolumn{5}{|c|}{ Elemental analysis } \\
\hline \multicolumn{5}{|l|}{ SEM-EDS / wt. \% } \\
\hline $\mathrm{C}$ & $59.85 \pm 0.75$ & $62.79 \pm 0.26$ & $70.88 \pm 7.97$ & $71.05 \pm 2.10$ \\
\hline $\mathrm{O}$ & $12.20 \pm 0.45$ & $9.57 \pm 0.17$ & $11.86 \pm 5.08$ & $6.19 \pm 1.97$ \\
\hline $\mathrm{Si}$ & n.d. & $0.29 \pm 0.17$ & n.d. & $0.27 \pm 0.13$ \\
\hline $\mathrm{Fe}$ & $26.77 \pm 1.13$ & $27.13 \pm 0.34$ & $14.99 \pm 6.49$ & $22.29 \pm 4.28$ \\
\hline \multicolumn{5}{|l|}{ XPS / at. \% } \\
\hline $\mathrm{C} 1 \mathrm{~s}$ & $86.18 \pm 6.88$ & $74.79 \pm 1.14$ & $81.95 \pm 0.64$ & $83.9 \pm 2.47$ \\
\hline $\mathrm{O} 1 \mathrm{~s}$ & $12.74 \pm 6.79$ & $18.51 \pm 0.37$ & $13.99 \pm 1.21$ & $11.8 \pm 2.38$ \\
\hline $\mathrm{Na} 1 \mathrm{~s}$ & & $0.29^{\mathrm{a}}$ & $1.60 \pm 1.31$ & \\
\hline $\mathrm{Mg} 1 \mathrm{~s}$ & & $0.62^{\mathrm{a}}$ & & \\
\hline $\mathrm{P} 2 \mathrm{p}$ & & & $1.73 \pm 1.38$ & \\
\hline Fe $2 p$ & $0.60 \pm 0.60$ & $1.73 \pm 0.01$ & $0.18 \pm 0.04$ & $0.6 \pm 0.21$ \\
\hline $\mathrm{Ca} 2 \mathrm{p}$ & & $1.12 \pm 0.16$ & & \\
\hline S $2 p$ & & $0.54 \pm 0.15$ & & \\
\hline Si $2 p$ & $0.49 \pm 0.51$ & $1.81 \pm 0.37$ & $1.15^{\mathrm{a}}$ & $3.4 \pm 0.28$ \\
\hline
\end{tabular}

${ }^{a}$ Data of only one point (the element was not detected at duplicate measurement). $\mathrm{S}_{\mathrm{BET}}$ : Brunauer, Emmett and Teller (BET) surface area; Diam ${ }_{\text {MICRO }}$ micropores diameter; $\mathrm{V}_{\text {TOTAL }}$ : total pore volume; $\mathrm{V}_{\text {MICROPORES }}$ : micropores volume; $\mathrm{V}_{\text {MESOPORES }}$ : mesopores volume; SEM-EDS: scanning electron microscopy with energy dispersive spectroscopy; XPS: X-ray photoelectron spectroscopy; n.d.: not detected; at.\%: atomic percentage.

From the Fe7 fabrics TG curves it was possible to observe clearly a disturbance at $882.5 \pm 7.8 \mathrm{~K}$ for cotton and $940.5 \pm 6.8 \mathrm{~K}$ for polyester based fabrics (Figure S15, SI section), with an endothermic reaction with a mass loss of $2.2 \pm 0.2$ for pure cotton and polyester, and $4.2 \pm 0.1$ for Poly/Elast. This is a signal not present at iron nitrate alone, nor at pure fabrics. The endothermic reaction should be indicating the transformation of the $\mathrm{Fe}_{\mathrm{x}} \mathrm{C}_{\mathrm{y}}$ into iron oxides $\left(\mathrm{Fe}_{\mathrm{x}} \mathrm{O}_{\mathrm{y}}\right)$ releasing $\mathrm{CO} / \mathrm{CO}_{2}$, leading to the mass loss. As a complete transformation of $\mathrm{Fe}_{3} \mathrm{C}$ into magnetite $\left(\mathrm{Fe}_{3} \mathrm{O}_{4}\right)$ would give a mass reduction of $6 \%$, not all carbon from the carbide is released as gas but remains in the solid matrix as carbon. On the other hand, the disturbance disappeared or is too small to be observed at Dye.Fe7 fabrics TG results. In the absent of oxygen, $\mathrm{Fe}_{\mathrm{x}} \mathrm{C}_{\mathrm{y}}$ is unstable above $973 \mathrm{~K}$, and form metallic $\mathrm{Fe}\left(\mathrm{Fe}_{3} \mathrm{C} \rightarrow 3 \mathrm{Fe}+\mathrm{C}\right){ }^{39}$ which $\mathrm{C}$ is solid carbon, being incorporated into the solid matrix, and not released as gas. The "absence of oxygen" to form elemental $\mathrm{Fe}$ in
Dye.Fe systems, could be explained from the adsorption mechanism proposed previously (capture of the dyes on the fabric surface by the Fe aquacomplex). After adsorption, the spent fabric is recovered and dried. Thus, the water molecules from the aquacomplex are released, but the Fe ion remains on the fabric surface surrounded by the dye molecules. Therefore, when pyrolyzed, Fe has less contact to the oxygen from the cellulose to be oxidized. This assumption should be further investigated. The oxygen from $-\mathrm{SO}_{2}$ and $-\mathrm{SO}_{3}$ groups of the dye will not be used for the oxidation of the Fe ion, as they gasify quickly, not interacting with the carbon matrix. Sulfur was not found in any of the analytical techniques (SEM-EDS, XPS) in three of the four MACs, confirming this assumption. The only exception was MAC.WPoly/Elast, with a very low amount $(0.5 \%)$ in the XPS. The smooth descendent curve in TG is due to the release of $\mathrm{SO}_{2}, \mathrm{CO}$, $\mathrm{CO}_{2}$ and $\mathrm{N}_{2}$ from thermal degradation of cellulose and dye structure. ${ }^{39}$ In the case of Fe7 fabrics, the iron is in 
the form of hydroxides due to the heating degradation of iron nitrate (equation 1), as well as the presence of $\mathrm{NO}_{3}$ and $\mathrm{HNO}_{3}$. Therefore, high amount of oxygen element is present to the formation of iron oxide.

Carbon content on the shallow surface $(<1 \mathrm{~nm})$ measured by XPS was higher (74-86\%) than that measured by EDS (60-71\%) in all cases. Therefore, it can be considered that $\mathrm{Fe}$ and other elements are in higher concentration inside the carbon structure. These results confirm our previous findings ${ }^{7}$ on white cotton fabrics based dye adsorption and MAC production even changing fiber type to polyester and its blending with cotton or elastane.

Fe content in the MAC.Dye.RPoly is the lowest from both EDS (15 wt.\%) and XPS (0.18 wt.\%) measurements. This fact converges with the visual impression that iron adsorption/impregnation on polyester fiber is not so good as with cotton and Poly/Elast blended fiber fabric. In the other hand MAC.WPoly/Elast presented the higher Fe content (27 wt.\% by EDS, 1.7 wt.\% by XPS) among the four, confirming a better $\mathrm{Fe}$ impregnation because of the elastane presence. High resolution scan for $\mathrm{C} 1 \mathrm{~s}, \mathrm{O} 1 \mathrm{~s}$ and $\mathrm{Fe} 2 \mathrm{p}$ were also performed. Before deconvolution all scan energy was calibrated to $284.5 \mathrm{eV}$ at $\mathrm{C}=\mathrm{C}$ signal (graphitic-like C).

$\mathrm{Fe} 2 \mathrm{p}$ deconvolution did not demonstrate metallic $\mathrm{Fe}$ component at low energy ca. $706.7 \mathrm{eV}$. Fe oxidized components present complex multiplex, which is very difficult to separate and conclusively determine the compost and oxidation state. Therefore, it is important to analyze in conjunction to the $\mathrm{O} 1 \mathrm{~s}$ deconvolution. When metallic oxide is present, $\mathrm{O} 1 \mathrm{~s}$ exhibits a component at around $530 \mathrm{eV}$, a slightly lower energy value than the adventitious $\mathrm{O}$ at approximately $532.5 \mathrm{eV}$. MAC.Poly/Elast demonstrated the higher metallic oxide component among samples, which is consistent to the XRD results. Although it was identified metallic Fe by XRD on the MAC.Dye, it was not confirmed on the shallow surface by XPS. Metallic Fe should be inside the carbon structure.

From the magnetism analysis, heating the sample under fixed external magnetic field $(\mathrm{M} \times \mathrm{T}$ heating) will lead the magnetic compounds into the Curie temperature, where the magnetic compound will no longer answer for the external field. As the Curie temperature is inherent for each compound, this is a complementary technique to elucidate the chemical structure of the magnetic compounds. This was performed on MAC.WCotFe7, which a $\mathrm{Fe}_{3} \mathrm{O}_{4}$ presence was determined by XRD. In the $\mathrm{M} \times \mathrm{T}$ measurement (Figure 5), the magnetic response decreases slowly from the beginning of the heating, abruptly decreasing the response at around $867 \mathrm{~K}$, this is very near to the $\mathrm{Fe}_{3} \mathrm{O}_{4}$ Curie temperature of $858 \mathrm{~K}$.

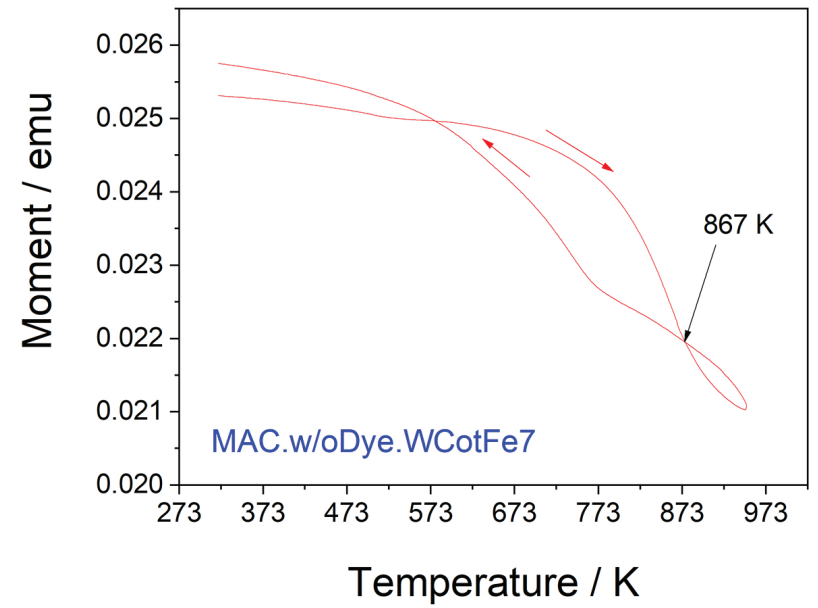

Figure 5. Magnetization vs. temperature curve for MAC derived from WCotFe7.

Above that temperature, there is still remaining a magnetic response, which should correspond to the metallic $\mathrm{Fe}$ response, as this compost have a higher Curie temperature of $1043 \mathrm{~K}$. This fact confirms that metallic Fe formation is feasible even in lower temperatures.

To our best knowledge, there are no reports on the formation and loading of elemental metallic Fe on carbon supports, in a real one-step process. Commonly $\mathrm{Fe}^{3+}$ and $\mathrm{Fe}^{2+}$ salts are reduced and co-precipitated to form magnetite. Then, magnetite is loaded on to the support by annealing. Moreover, a washing step, commonly with alcohol and water, or acid, is required to clean any sub-products or non-well loaded species. ${ }^{16}$ Additionally, the development of an ordered mesoporous carbon usually applies templates that requires to be removed from the carbon matrix after production, generating more wastewater. ${ }^{18,40}$ Due to the Fe specie impregnation the pore area usually is not so high, ${ }^{41,42}$ when simple methods are applied $\left(190 \mathrm{~m}^{2} \mathrm{~g}^{-1}\right)$. To increase pore development $\left(\mathrm{S}_{\mathrm{BET}}\right.$ as high as $\left.1.012 \mathrm{~m}^{2} \mathrm{~g}^{-1}\right)$ several treatments are made. ${ }^{43}$ Table 3 summarizes some representative MAC properties applied in adsorption, compared to this study.

\section{Adsorption capacity comparison}

From the kinetics curve (Figure 6a), it was observed that the two MACs applied had significant different adsorption performances. The carbon prepared with $2 \mathrm{~h}$ isotherm (MAC.WCotFe14 (2 h)), had 4.2 times higher dye adsorption capacity than the carbon prepared with no isotherm time (MAC.WCotFe7 (0 h)), i.e., temperature was increased up to $973 \mathrm{~K}$ and heating was stopped, both produced from white cotton. MAC prepared with no isotherm had worse performance than fabric WCotFe7 without carbonization and activation. This difference can 
Table 3. MAC properties comparison with literature

\begin{tabular}{|c|c|c|c|c|c|}
\hline \multirow{2}{*}{ MAC precursor } & \multicolumn{2}{|c|}{$\mathrm{S}_{\mathrm{BET}}$} & \multirow{2}{*}{ Mesoporous / nm } & \multirow{2}{*}{ Application } & \multirow{2}{*}{ Reference } \\
\hline & Without $\mathrm{Fe}$ & With Fe & & & \\
\hline Bayberry kernel and formaldehyde & 1385 & 1012 & $3.55 / 3.85$ & $\mathrm{~Pb}$ and $\mathrm{Cr}$ adsorption & Li et $a .^{43}$ \\
\hline Polymer on SBA template & 607 & 466 & $3.68 / 3.65$ & As adsorption & Gu et al..$^{18}$ \\
\hline Sucrose on SBA template (Ni based) & not determined & 387 & 4.62 & multi metals adsorption & Guo et al..$^{40}$ \\
\hline Cotton fabric $+1 \mathrm{~mol} \mathrm{~L}^{-1}$ iron nitrate & 295 & $190 / 91$ & microporous (1-2) & Cr adsorption & Zhu et $a l^{41}$ \\
\hline Pinewood + hematite & 209 & 193.1 & no information & As adsorption & Wang et al. ${ }^{42}$ \\
\hline Cotton fabric $+0.3 \mathrm{~mol} \mathrm{~L}^{-1}$ iron nitrate & not determined & $498 \pm 40$ & 4-5 (3-4 also present) & reactive dye adsorption & this study \\
\hline
\end{tabular}

MAC: magnetic activated carbon; $\mathrm{S}_{\mathrm{BET}}$ : Brunauer, Emmett and Teller (BET) surface area; SBA: Santa Barbara Amorphous type mesoporous silica.

be explained by the different pore development (Figure 6b) that each carbon had under the different carbonization conditions. The carbon prepared with no isotherm time $(0 \mathrm{~h})$ lead to predominantly micropore carbon $\left(\mathrm{V}_{\text {MICROPORE }}\right.$ : $0.140 \mathrm{~cm}^{3} \mathrm{~g}^{-1}, 82 \%$ of $\mathrm{V}_{\text {Total }}$ ), while the carbon prepared under $2 \mathrm{~h}$ isotherm $(2 \mathrm{~h})$ developed more mesopores $\left(\mathrm{V}_{\text {MESOPORES }}: 0.175 \mathrm{~cm}^{3} \mathrm{~g}^{-1}, 38 \%\right.$ of $\left.\mathrm{V}_{\text {Total }}\right)$, concentrated between 4 to $5 \mathrm{~nm}$ sizes. As the dye utilized, RB5 has a large molecule size of $2.9 \times 1.5 \mathrm{~nm}$ calculated from $\mathrm{ACD} /$ ChemSketch $^{44}$ with $3 \mathrm{D}$ optimization, mesoporous play an important role in the physical adsorption process. Ip et al..$^{45}$ had calculated a molecule size with difference in the width of $0.86 \mathrm{~nm}$ and length of $2.99 \mathrm{~nm}$ utilizing the Computer Aided Chemistry (CAChe) software ${ }^{46}$ system (Figure S3, SI section).

Table 4 summarizes some representative adsorbents tested for RB5 removal from water solution, compared to this study. From these data is possible to conclude that the following conditions are important for effective RB5 removal: high pore area, high mesopore volume, acid $\mathrm{pH}$, salt presence.

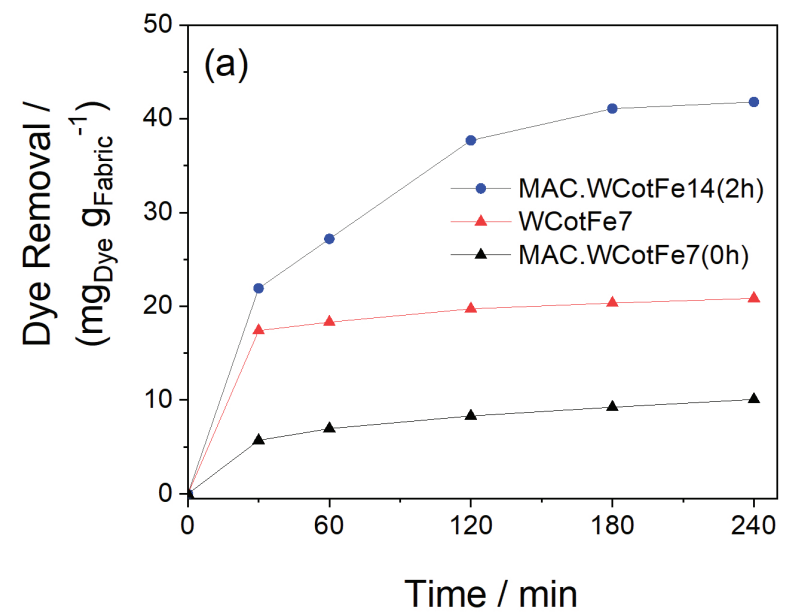

\section{Conclusions}

The study presented here is an all in one solution. The iron nitrate impregnated into the fabric helps to decrease the $\mathrm{pH}$ to acidic range where the reactive dyes are better adsorbed, as well as forms positive iron aquacomplexes which captures the negative dye molecule. This adsorbent can be used in all $\mathrm{pH}$ range of a dyeing process from 3 to 12 , without adding chemicals for $\mathrm{pH}$ adjustment. Separation of the Fe-fabric adsorbent is very easy, as they are in the fabric form, not powder as usual adsorbents. Carbon surface functionalization is a well-known technique to enhance properties for specific applications. Fe doping on carbons is used to enhance adsorption of positive charged pollutants as heavy metals, but for our best knowledge, it is the first time that Fe doping is used in a waste derived adsorbent to enhance adsorption of negative charged pollutants, as the reactive dyes.

Moreover, the spent adsorbent has its own application, as precursor of MAC. The MAC preparation method applied in this study has several advantages: $(i)$ direct

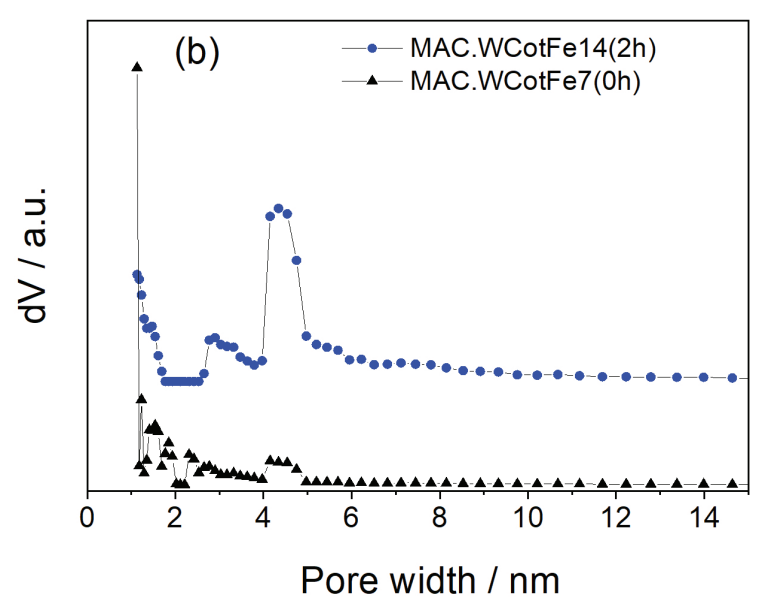

Figure 6. (a) Reactive black dye adsorption kinetics of MAC (200 mg of adsorbent for $50 \mathrm{~mL}$ dye solution, just dye water solution, no synthetic solution); (b) DFT pore size distribution of MAC prepared with $2 \mathrm{~h}$ isotherm and with no isotherm, from white cotton impregnated with $\mathrm{Fe}\left(\mathrm{NO}_{3}\right)_{3}$. 
Table 4. RB5 adsorption capacity comparative between waste derived and commercial AC adsorbents

\begin{tabular}{|c|c|c|c|c|}
\hline Reference & Adsorbent & $\mathrm{S}_{\mathrm{BET}} /\left(\mathrm{m}^{2} \mathrm{~g}^{-1}\right)$ & Dye solution & Adsorption capacity / $\left(\mathrm{mg} \mathrm{g}^{-1}\right)$ \\
\hline Cunico et al..$^{19}$ & coal power plant ash & 2.85 & water solution & 5.7 in $6 \mathrm{~h}$ \\
\hline Ip et al..$^{45}$ & peat/bone char/F400 AC & $\begin{array}{l}0.7 / 107(9 \mathrm{~nm}) \\
793(2.4 \mathrm{~nm})\end{array}$ & water solution with $\mathrm{NaCl}$ & $\begin{array}{c}5.4 / 171 / 173 \\
29.8 / 168 / 319\end{array}$ \\
\hline Al-Degs et al..$^{47}$ & F400 AC & 1100 & water solution & 434 (3 weeks for equilibrium) \\
\hline Furlan et al..$^{33}$ & coconut shell AC & 754 & $\mathrm{NaCl}, 343 \mathrm{~K}$ & 95 in $5 \mathrm{~h} 40 \mathrm{~min}, \mathrm{pH}=3$ \\
\hline \multirow{2}{*}{ Cardoso et al. ${ }^{28}$} & pine shell & not informed & water solution, $313 \mathrm{~K}$ & $\begin{array}{l}64.8 \text { at } \mathrm{pH}=2,12 \mathrm{~h} \\
\text { removal } 0 \% \text { at } \mathrm{pH}>6\end{array}$ \\
\hline & pine shell AC & not informed & water solution, $313 \mathrm{~K}$ & $\begin{array}{l}428.2 \text { at } \mathrm{pH}=2,4 \mathrm{~h} \\
\text { removal } 0 \% \text { at } \mathrm{pH}>10\end{array}$ \\
\hline Lucio et al. ${ }^{29}$ & activated carbon felt (commercial) & $\begin{array}{c}1,112 \\
\text { highly microporous }\end{array}$ & room temperature & $\begin{array}{c}20 \text { at } \mathrm{pH}=1.5 \\
9.5 \text { at } \mathrm{pH}=7\end{array}$ \\
\hline This work & $\begin{array}{c}\text { Fe modified cotton } \\
\text { MAC derived from cotton fabric }\end{array}$ & $\begin{array}{l}<10 \\
289\end{array}$ & $\mathrm{NaCl}, 313 \mathrm{~K}$ & $\begin{array}{c}31 \text { at } \mathrm{pH}=10, \text { in } 1 \mathrm{~h} \\
41 \text { at } \mathrm{pH}=10, \text { in } 3 \mathrm{~h} \\
\text { (not maximum capacity) }\end{array}$ \\
\hline
\end{tabular}

$\mathrm{S}_{\mathrm{BET}}$ : Brunauer, Emmett and Teller (BET) surface area; MAC: magnetic activated carbon; AC: activated carbon.

elemental Fe loading, which gives higher magnetization and catalyst property; (ii) ordered mesoporous development at range 3-4 and 4-5 $\mathrm{nm}$, without template application; (iii) no wastewater generation from carbon washing to remove templates from the matrix; (iv) relatively high $\mathrm{S}_{\mathrm{BET}}$ even with Fe specie impregnated, (v) very simple, fast simultaneous carbonization, activation, magnetization method and (vi) MAC pore size and magnetic specie can be designed accordingly to the required application, by changing the pyrolysis condition, and adsorption steps.

Each type of fabric should have different approaches. For instance, pure polyester fabric did not have good Fe retention in water solution, therefore, this type of fabric should not be used as adsorbent, but directly as MAC precursor. On the other hand, polyester blended with elastane showed surprisingly high color removal and MAC properties, therefore should be used first for dye removal, and then pyrolyzed to MAC. Social impact is also relevant in countries like Brazil. Including the fabrics as a "recyclable" item, it will increase the income of recycling agents, decrease municipal solid waste collection costs and extend landfill lifetime.

\section{Supplementary Information}

Supplementary information is available free of charge at http://jbcs.sbq.org.br as PDF file.

\section{Acknowledgments}

This work was supported by FAPESP (projects No. 2017/24931-4, 2012/50718-2, 2011/51902-9), FINEP, CAPES (finance code 001), CNPq (project No. 404843/2018-2,
142238/2016-3, 470481/2012), Brazilian Electricity Regulatory Agency (ANEEL PD-0553-0022/2012), Brazilian Oil and Gas Company (PETROBRAS). The authors also acknowledge Dairix and Multi-User Central Facilities at UFABC for analytical support.

\section{Author Contributions}

Wagner A. Carvalho was responsible for supervision, conceptualization, funding acquisition, general methodology, writing-review and editing; Jenny S. Komatsu for project administration, conceptualization, general investigation and methodology, writing original draft preparation; Beatriz M. Motta for reactive dye adsorption investigation and methodology; Rodolfo S. Tiburcio for thermal analysis and energy dispersive spectroscopy investigation; Ana M. Pereira Neto for funding acquisition, thermal analysis and energy dispersive, investigation and methodology; Pol W. G. de Pape for X-ray diffraction and X-ray fluorescence spectroscopy investigation and methodology; Dalmo Mandelli for funding acquisition, general conceptualization, carbon methodology.

\section{References}

1. Guerrero-Lemus, R.; Shephard, L. E. In Lecture Notes in Energy, vol. 38; Springer Verlag: Cham, CH, 2017.

2. Pensupa, N.; Leu, S.-Y.; Hu, Y.; Du, C.; Liu, H.; Jing, H.; Wang, H.; Lin, C. S. K.; Top. Curr. Chem. 2017, 375, 76.

3. https://www.fashionatingworld.com/new1-2/world-productionof-all-fiber-rises-in-2018-natural-fibers-on-the-rise, accessed in November 2020. 
4. Bilińska, L.; Gmurek, M.; Ledakowicz, S.; Chem. Eng. J. 2016 , 306, 550.

5. Bilinska, L.; Gmurek, M.; Ledakowicz, S.; J. Adv. Oxid. Technol. 2015, 18, 185.

6. Kyzas, G. Z.; Fu, J.; Matis, K. A.; Materials 2013, 6, 5131.

7. Komatsu, J. S.; Souza, F. M.; Pinheiro, V. S.; Böhnstedt, P.; de Pape, P. W. G.; Mandelli, D.; Santos, M. C.; Carvalho, W. A.; Catal. Today, in press, DOI: 10.1016/j.cattod.2020.09.003

8. Azari, A.; Nabizadeh, R.; Nasseri, S.; Mahvi, A. H.; Mesdaghinia, A. R.; Chemosphere 2020, 250, 126238.

9. Ahmed, M. J.; J. Environ. Chem. Eng. 2016, 4, 89.

10. Xu, Z.; Yuan, Z.; Zhang, D.; Chen, W.; Huang, Y.; Zhang, T.; Tian, D.; Deng, H.; Zhou, Y.; Sun, Z.; J. Cleaner Prod. 2018, 192, 453.

11. Yu, X.; Wang, S.; Zhang, J.; J. Mater. Sci. 2018, 53, 5458.

12. Mendoza-Carrasco, R.; Cuerda-Correa, E. M.; AlexandreFranco, M. F.; Fernández-González, C.; Gómez-Serrano, V.; J. Environ. Manage. 2016, 181, 522.

13. Yoda, T.; Shibuya, K.; Myoubudani, H.; J. Text. Sci. Fashion Technol. 2018, 125, 572.

14. Hudson, R.; Feng, Y.; Varma, R. S.; Moores, A.; Green Chem. 2014, 16, 4493.

15. Thines, K. R.; Abdullah, E. C.; Mubarak, N. M.; Ruthiraan, M.; Renewable Sustainable Energy Rev. 2017, 67, 257.

16. Siddiqui, M. T. H.; Nizamuddin, S.; Baloch, H. A.; Mubarak, N. M.; Al-Ali, M.; Mazari, S. A.; Bhutto, A. W.; Abro, R.; Srinivasan, M.; Griffin, G.; J. Environ. Chem. Eng. 2019, 7, 102812.

17. Yang, Q.; Shi, Y.; Fang, Y.; Dong, Y.; Ni, Q.; Zhu, Y.; Fu, Y.; Compos. Sci. Technol. 2019, 174, 176.

18. Gu, Z.; Deng, B.; Yang, J.; Microporous Mesoporous Mater. 2007, 102, 265.

19. Cunico, P.; Kumar, A.; Fungaro, D. A.; J. Nanosci. Nanotechnol. 2015, 1, 148.

20. Silva, K. K. O. S.; Paskocimas, C. A.; Oliveira, F. R.; Nascimento, J. H. O.; Zille, A.; Desalin. Water Treat. 2016, 57, 2640.

21. Ho, Y.-S.; Scientometrics 2004, 59, 171.

22. McKay, G.; Poots, V. J. P.; J. Chem. Technol. Biotechnol. 1980, 30, 279.

23. Mitrogiannis, D.; Psychoyou, M.; Baziotis, I.; Inglezakis, V. J.; Koukouzas, N.; Tsoukalas, N.; Palles, D.; Kamitsos, E.; Oikonomou, G.; Markou, G.; Chem. Eng. J. 2017, 320, 510.

24. Chaudhary, G. R.; Saharan, P.; Kumar, A.; Mehta, S. K.; Mor, S.; Umar, A.; J. Nanosci. Nanotechnol. 2013, 13, 3240.

25. Acevedo, B.; Barriocanal, C.; Lupul, I.; Gryglewicz, G.; Fuel 2015, 151, 83 .

26. da Silva, J. E.; Rodrigues, F. I. L.; Pacífico, S. N.; Santiago, L. F.; Muniz, C. R.; Saraiva, G. D.; do Nascimento, R. F.; Sousa Neto, V. D. O.; Rev. Virtual Quim. 2018, 10, 1248.
27. Beekaroo, D.; Mudhoo, A. In SpringerBriefs in Green Chemistry for Sustainability; Sharma, S. K., ed.; Springer: Heidelberg, 2012, p. 15

28. Cardoso, N. F.; Pinto, R. B.; Lima, E. C.; Calvete, T.; Amavisca, C. V.; Royer, B.; Cunha, M. L.; Fernandes, T. H. M.; Pinto, I. S.; Desalination 2011, 269, 92.

29. Lucio, D.; Laurent, D.; Ux; Roger, G.; Carbon: Sci. Technol. 2008, 1, 1965.

30. Wieczorek-Ciurowa, K.; Kozak, A. J.; J. Therm. Anal. Calorim. 1999, 58, 647.

31. Lima, R. N.; Abreu, F. O. M. S.; Rev. Virtual Quim. 2018, 10, 709.

32. Teixeira, A. P. C.; Tristão, J. C.; Araujo, M. H.; Oliveira, L. C. A.; Moura, F. C. C.; Ardisson, J. D.; Amorim, C. C.; Lago, R. M.; J. Braz. Chem. Soc. 2012, 23, 1579.

33. Furlan, F. R.; da Silva, L. G. M.; Morgado, A. F.; de Souza, A. A. U.; de Souza, S. M. A. G. U.; Resour., Conserv. Recycl. 2010, 54, 283.

34. Gang, D.; Ahmad, Z. U.; Lian, Q.; Yao, L.; Zappi, M. E.; Chem. Eng. J. 2021, 403, 126286.

35. Ferrero, F.; Periolatto, M.; Chem. Eng. Trans. 2011, 25, 1037.

36. Kyzas, G.; Christodoulou, E.; Bikiaris, D.; Processes 2018, 6, 166.

37. Park, S.; Baker, J. O.; Himmel, M. E.; Parilla, P. A.; Johnson, D. K.; Biotechnol. Biofuels 2010, 3, 10.

38. Wang, J.; Li, X.; Ge, F.; Cai, Z.; Gu, L.; ACS Sustainable Chem. Eng. 2016, 4, 3285.

39. Aparicio, C.; Filip, J.; Machala, L.; Powder Diffr. 2017, 32, S207.

40. Guo, W.; Meng, X.; Liu, Y.; Ni, L.; Hu, Z.; Chen, R.; Meng, M.; Wang, Y.; Han, J.; Luo, M.; J. Ind. Eng. Chem. 2015, 21, 340.

41. Zhu, J.; Gu, H.; Guo, J.; Chen, M.; Wei, H.; Luo, Z.; Colorado, H. A.; Yerra, N.; Ding, D.; Ho, T. C.; Haldolaarachchige, N.; Hopper, J.; Young, D. P.; Guo, Z.; Wei, S.; J. Mater. Chem. A 2014, 2, 2256.

42. Wang, S.; Gao, B.; Zimmerman, A. R.; Li, Y.; Ma, L.; Harris, W. G.; Migliaccio, K. W.; Bioresour. Technol. 2015, 175, 391.

43. Li, K.; Zhou, Y.; Li, J.; Liu, J.; J. Taiwan Inst. Chem. Eng. 2018, 82,312

44. ACD/ChemSketch, version 12.1.0.31258; Advanced Chemistry Development, Inc., Toronto, Canada, 2019.

45. Ip, A. W. M.; Barford, J. P.; McKay, G.; J. Colloid Interface Sci. 2009, 337, 32.

46. Scigress Explorer, version 77047; Fujitsu Ltd., Tokyo, Japan, 2009.

47. Al-Degs, Y.; Khraisheh, M. A. M.; Allen, S. J.; Ahmad, M. N.; Water Res. 2000, 34, 927.

Submitted: November 20, 2020

Published online: December 16, 2020 